\author{
Анна А. Зализняк, Е. В. Падучева \\ ${ }^{1}$ Институт языкознания РАН \\ ФИЦ «Информатика и управление» РАН \\ Государственный институт русского языка им. А. С. Пушкина \\ (Россия, Москва) \\ anna.zalizniak@gmail.com
}

\title{
О СЛОВЕ ОТНЮДЬ *
}

В статье предлагается анализ семантики и условий употребления русского слова отнюдь. Демонстрируется, что семантический вклад слова отнюдь в значение отрицательного предложения определяется тем, что оно производит усиление отрицания в двух отношениях - дескриптивном и иллокутивном. Парадигматическим контекстом для употребления отнюдь является контекст антонимического отрицания, т.е. отрицания скалярного признака, встроенного в биполярную шкалу. Отрицание не $P$ в таком случае переключает значение на противоположный полюс шкалы, т.е., помимо компонента 'неверно, что Р', включает еще утверждение наличия некоторого $\mathrm{Q}$, являющегося полноценным семантическим признаком, противоположным по отношению к Р. Дескриптивная функция слова отнюдь состоит в том, что в контексте предикатов, имеющих антонимическое отрицание, оно вносит смысл высокой степени реализации противоположного $\mathrm{P}$ признака Q. Иллокутивная функция состоит в увеличении силы опровержения общепринятого или высказанного в предтексте мнения. В случае невозможности встроить признак в биполярную шкалу и одновременно отсутствия некоторого имеющегося заранее мнения, опровержением которого служило бы данное высказывание, отнюдь не может выполнять ни одну из двух своих функций и его употребление невозможно.

Ключевые слова: русский язык, семантика, отрицание, дискурсивные слова, иллокутивная сила, биполярная шкала.

Слово отнюдь на первый взгляд кажется несколько устаревшим; так, большинство опрошенных нами носителей русского языка сказали, что сами этого слова

* Статья написана при поддержке Российского научного фонда, проект № 18-18-00462 «Коммуникативно-синтаксический интерфейс: типология и грамматика», реализуемый в Государственном институте русского языка им. А.С. Пушкина. 
в речи не употребляют. Однако материал «Национального корпуса русского языка» [НКРЯ] этого не подтверждает: частота употребления слова отнюдь на протяжении 150 лет увеличилась — и продолжает расти, в том числе в течение последних 50 лет $^{2}$. Это обстоятельство представляет тем больший интерес, что значение этого слова за это время существенно сузилось.

Согласно словарю Фасмера [3: 172], отнюдь соответствует др.-рус. om( om(b) инуду 'совсем', 'со всех сторон' (от основы ин- 'иной'). В современном языке отнюдь не в некоторых контекстах сближается с нисколько не, ничуть не, совсем не, вовсе не, никак не, далеко не - но при этом не синонимично ни одному из этих слов.

Для современного русского языка мы будем различать следующие типы употребления отнюдь.

1. Слово отнюдь находится внутри предложения, непосредственно перед отрицанием не.

1a. В предложении с отрицанием при глаголе, прилагательном или наречии, ср. ${ }^{3}$ :

(1) До определенного момента это была структура СССР, потом новая действительность, которая его отнюдь не радовала (А. Кушнир, Я. Шенкман. Абсолютно несистемный центробежный человек. 2013);

(2) Евгения Васильевна была, как мне кажется, женщиной неоднозначной, но отнюдь не глупой (А. Маринина. Последний рассвет. 2013);

(3) Слова Иванько, что еще все поплящут, отнюдь не пустая угроза (В. Войнович. Иванькиада, или Рассказ о вселении писателя Войновича в новую квартиру. 1976);

(4) ...а чего стоит сам цииферблат: выпуклый, треугольный, по краям выложены 69 бриллиантов. И забавно, и выглядит отнюдв не дешево (Е. Блинова. Время не имеет значения. 2002).

1b. В предложении с отрицанием при местоимениях все, всегда и всякий:

(5) Мощная и богатая Германия способна вызывать не меньшую зависть, да и немцев отнюдь не все любят (Известия. 25.09.2002);

(6) Ну а Мыша даже в самом благодушном его настроении отнюдь не всякий отважился бы погладить (М. Семенова. Волкодав: Знамение пути. 2003);

(7) Олимпиада - турнир крайне непредсказуемый и отнюдв не всегда основные претенденты на победу с легкостью добиваются своего (Известия. 10.11.2002).

1с. «Одиночное» отнюдь в конечной позиции, после предложения, содержащего отрицание; слово отнюдь отделено запятой или же составляет отдельное

2 По данным [НКРЯ], в период 1871-1970 гг. частота слова отнюдь составляла 31,6 ipm (4 082 на 129168725 словоупотреблений), в период 1971-2000 гг. — 41,8 ipm (2 700 на 64505247 словоупотреблений), в период 2001-2019 гг. — 48 ipm (3 277 на 68874126 словоупотреблений.

3 Здесь и далее: примеры со ссылкой в круглых скобках взяты из [НКРЯ]. 
предложение, при этом оно как бы «вынесено» в конец и в принципе может быть «возвращено на место» (ср. для примеров (8)-(10): отнюдь не носило характер произвола, отнюдь не дурак, отнюдь не процветающий):

(8) Все это не носило характера произвола, отнюдь (В. Т. Шаламов. Колымские рассказы. 1954-1961);

(9) Подозреваю, правда, что Рощин просто прикололся на твой счет -он же не дурак, отнюдь (Е. Завершнева. Высотка. 2012);

(10) Не процветающий, скажу вам, у заведения вид. Отнюдь. Откуда ж гравюpы? (Д. Рубина. Окна. 2011);

Помимо простого отрицания, возможен оборот не то чтобы $P$ :

(11) Не то чтобы мне хотелось фамильярности - отнюдь (В. Белоусова. Второй выстрел. 2000);

(12) Не то чтобы он себя изжил, исчерпал, - отнюдь (Мир \& Дом. Сity. 15.10.2003).

Ср.: Мне отнюдь не хотелось фамильярности; Он отнюдь себя не изжил.

2. Слово отнюдь составляет отдельное предложение. Его функция состоит в опровержении мнения, высказанного в предыдущем предложении. Здесь возможны следующие варианты.

2a. Опровергаемое мнение вводится предикатом мнения, сопровождаемым указанием на его ошибочность, ср.:

(13) Однако было бы ошибкой считать, что книга Плотникова посвящена исключительно возвышенно-метафизическим предметам. Отнюдь. <..> автор фокусирует внимание читателя и на вещуах, так сказать, приземленных, а то и вовсе легкомысленных (Н. Лукас. О кн. Николая Плотникова «Deutschland? Aber wo liegt es?». 2003);

(14) Однако не надо думать, что этим промыслом занимаются одни только цъыганки. Отнюдь (Криминальная хроника. 24.07.2003);

(15) На первый взгляд кажется, что эти два сообщества и ужиться-то вместе не смогут. Отнюдь. Они близнецьь-братья (Знание - сила. 2003);

(16) На моих изумленньх глазах страж откальввает булавку внутреннего кармана зверевского пиджака и достает увесистый сверток денег... Это не значит, что художник был жадным. Отнюдь. <...> Деньги ему были нужны для чего-то важного. Скажем, на краски (3. Плавинская. Отражение. 2003).

2b. Опровергаемое мнение вводится в форме вопроса (часто содержащего тот или иной показатель сомнения):

(17) Катя начала тосковать. И тосковать, и ревновать, что было особенно неприятно. Вначале здорово злилась на себя и иронизировала и даже 
пыталась презирать. <..> Несносный отвратительный тип. Разве Катя была слепа? Отнюдь. Но это не имело никакого значения. Она попалась (М. Зосимкина. Ты проснешься. Книга первая. 2015);

(18) Может быть, это всего лишь его индивидуальный почерк? Отнюдь. Даже поверхностное знакомство с израильской тактической стрельбой дает ответ (А. Ларин. Последний довод телохранителя. 2004);

(19) Но все ли в то время разделяли точку зрения Бакатина? Отнюдь. Знало ли правительство о возросшей преступности? (Завтра. 04.02.2003);

(20) Очередной виток административной реформы? Отнюдь. Портфели делить рано (Итоги. 20.05.2003).

2c. Опровергаемое мнение высказано другим говорящим; отнюдь появляется в ответной реплике:

(21) - Мне кажется, что это довольно демагогическое понятие. - Отнюдь (В. Крапивин, Д. Струев. Дорога негаснущей надежды. 2015);

(22) - Порой складывается впечатление, что перспектива безвизового режима с ЕС настолько долгосрочна, что почти виртуальна... - Отнюдь. Сроки - это тоже предмет переговоров (Дипломатический вестник. 25.05.2004).

Обратим внимание на то, что в случае 2 вместо одиночного отнюдь может выступать отнюдь нет - в том же значении ${ }^{4}$, ср.:

(23) Может сложиться впечатление, что я газовик или нефтяник. Отнюдь нет. Я противник продажи сырьевых ресурсов и надеюсь, что Россия сможет в недалеком будущем торговать продуктами нефте- и газохимии, а не сырьем (Наука и жизнь. 2007);

(24) Казалось бы, столь катастрофическая ситуация с валютой должна была побудить советских руководителей позаботиться о всемерном сокращении валютных расходов. Отнюдь нет. Им и в этих условиях казалось невозможным отказаться от финансирования масштабной внешнеполитической деятельности (Е. Гайдар. Гибель империи. 2006);

(25) Каземат? Отнюдь нет. «У меня очень теплая и уютная комната, много света, и я вижу в окно кусок неба», - писал Бакунин своей знакомой Матильде Рейхель (Наука и жизнь. 2009).

В случае 2 слово отнюдь означает 'вовсе нет', т. е. представляет собой эмфатическое отрицание и используется говорящим для утверждения некоторой точки зрения в форме акцентированного опровержения противоположной точки зрения, в той или иной форме присутствующей в контексте высказывания.

${ }^{4}$ Современное отнюдь возникло в результате отпадения показателя отрицания в отрицательной конструкции и переноса ее значения на оставшийся элемент; ср. отпадение в определенных условиях отрицательной частицы ne во французском показателе отрицания ne pas (истор. букв. 'ни шагу' [Rey 2000/2: 2594]). 
Случай 1 составит предмет дальнейшего обсуждения.

Итак, что означает отнюдь не Р? Нужно получить ответы на два вопроса:

1) в каких случаях в отрицательное предложение можно и в каких нельзя «вставить» слово отнюдь;

2) каков семантический вклад этого слова в тех случаях, когда его вставка допустима.

Начнем со второго вопроса. Как представляется, слово отнюдь выполняет две функции - дескриптивную и иллокутивную. Рассмотрим следующие примеры:

(26) Ведь, как известно, ЮАР - единственная страна мира, добровольно прекратившая испьтания ядерного оружия. Однако исследования в области ядерной физики в связи с этим отнюдь не закончились (Знание - сила. 2011);

(27) Уили в прошлое времена контркультуры, но, как видим, ее ценности отнюдь не исчезли (Наука и религия. 2011) <а сохранились>;

(28) Хотя и существует запрет на нашу деятельность, она отнюдь не пресеклась (Б. Евсеев. Евстигней. 2010) <а продолжала существовать>;

(29) Альмушка стала тяжелей на подъем. Но обаяния своего отнюдь не лишилась. Особенно хороша была, когда играла на арфе (Б. Евсеев. Евстигней. 2010).

Во всех этих примерах не + глагол со значением 'перестать иметь место' означает 'продолжать иметь место': исследования не закончились = 'продолжаются'; ценности не исчезли = 'сохраняются', деятельность не пресеклась = 'продолжается', не лишилась обаяния = 'сохраняет обаяние' (ср. о типе антонимов 'P' — 'не-Р' в [Апресян 1974: 292]). Вставка слова отнюдь выполняет одновременно следующие две функции.

Во-первых, отнюдь усиливает степень реализации признака (= дескриптивная функция): исследования не просто продолжаются, а идут в полную силу, ценности не просто сохраняются, а достаточно сильны, деятельность не просто продолжается, а происходит интенсивно; обаяние все еще довольно сильное и т.д.

Во-вторых, отнюдь ув еличивает иллокутивную силу опроверже н и я (= иллокутивная функция): если предложение с отрицанием просто констатирует положение вещей, противоположное тому, которого можно было бы ожидать (а такая импликатура имеется во всяком отрицательном предложении), то предложение с отнюдь включает дополнительную «интонацию разубеждения»: ‘ты мог бы подумать, что Р; я говорю: Не P!; Перестань думать, что P'.

Рассмотрим подробнее функцию отнюдь, которую мы назвали дескрипт и в н о й.

Парадигматическим контекстом для употребления отнюдь является контекст обозначения скалярных признаков, встроенных в биполярную шкалу ('хорошо’ ‘плохо’, ‘много’ - ‘мало’ и т. п.). Отрицание не Р в таком случае переключает значение на противоположный полюс шкалы, т. е. (помимо компонента 'неверно, что 
P', уходящего на задний план) включает еще утверждение наличия некоторого Q, являющегося полноценным семантическим признаком, пр о т и о п о л о жы м по отношению к Р. Такое отрицание принято называть контрарным; для этого признака Q обычно существует лексическое выражение - антоним. Так не + хорошо утверждает не просто отсутствие признака 'хорошо', а наличие признака 'плохо', не + нравится обозначает однозначно негативную оценку и т. д. [ср.: Богуславский 1985: 35; Зализняк 2006: 379; Апресян 2006: 141; Падучева 2013: 238]. В [Богуславский 1985: 35] такое отрицание названо идиоматическим; мы будем называть его антонимическим. Эффект взаимодействия с отрицанием (т. е. будет оно обычным контрадикторным или антонимическим контрарным) определяется семантикой предиката. Антонимическое отрицание характерно для глаголов внутреннего состояния. При этом некоторые предикаты допускают обе возможности; так предложение $О$ н не любит свою жену содержит обычное отрицание ('неверно что любит', т. е. 'не испытывает любви'), а предложение Он не любит свою тещу, скорее всего, означает 'испытывает неприязнь', т. е. содержит антонимическое отрицание.

Семантический вклад слова отнюдь в контексте предикатов, имеющих антонимическое отрицание, состоит в том, что оно вносит смысл высокой степени реализации противоположного Р признака Q. Так отнюдь не радовала в примере (1) означает 'довольно сильно огорчала'; отнюдь не глупая - 'в достаточной степени умная' в (2), отнюдь не дешево — 'весьма дорого' в (3), отнюдь не пустая угроза — 'реальное намерение' в (4), отнюдь не все любят — 'многие не любят' в (5) и т. д. Ср. также:

(30) Райским истекшее дежурство отнюдь не было (Т. Соломатина. Девять месяцев, или «Комедия женских положений». 2010) <= было очень тяжелым >;

(31) ...я торопливо пробирался вперед, расталкивая челноков, сопровождавиих мое продвижение выражениями отнюдь не лестного свойства (Наука и религия. 2008) <= весьма негативного>;

(32) Вишневецкая наклонилась, и они обменялись быстрым, но отнюдь не бесстрастнылм поцелуем (Н. Леонов, А. Макеев. Ментовская крыша. 2004) $<=$ весьма страстным>.

Отличие семантики конструкции отнюдь не $P$ от прямого утверждения Q состоит в том, что она «усиливает» риторическую фигуру литоты, выражаемую отрицательной конструкцией 5 . В этом и состоит вклад слова отнюдь в семантику отрицательного предложения (т. е. ответ на второй вопрос).

Чтобы ответить на первый вопрос, рассмотрим более подробно условия, лицензирующие употребление слова отнюдь.

${ }^{5}$ Ср. определение литоты из [Квятковский 1966: 145]: «стилистическая фигура, определение какого-либо понятия или предмета путем отрицания противоположного»: Не дорого ценю я громкие права (Пушкин). 
Имеется по крайней мере два типа контекстов, где отнюдь усиливает степень реализации противоположного признака, указание на который уже содержится в конструкции с антонимическим отрицанием. Первый контекст - это оценочные предикаты (не радует, не глупьй, не бесстрастный, не дешевыц̆, примеры (1)(4)). Другой - контекст предикатов со значением 'перестать иметь место' (примеры (26)-(29)).

При этом в некоторых случаях слово отнюдь может само вносить значение контрарной противоположности, отсутствующее в конструкции с отрицанием. Так, если из примера (33) извлечь слово отнюдь, то не успокоил будет означать 'неверно, что успокоил' (обычное контрадикторное отрицание), т. е. состояние беспокойства сохранилось неизменным. При этом отнюдь не успокоил означает '(наоборот) разволновал, усилил беспокойство':

(33) Фомина разговор с Дмитревским тоже отнюдь не успокоил (Б. Евсеев. Евстигней. 2010).

Во фразе, соответствующей примеру (34), за вычетом слова отнюдь, сочетание не были переполнены может быть понято как содержащее либо обычное отрицание ('неверно, что были переполнены'), либо антонимическое отрицание ('были заполнены не целиком’); вставка отнюдь однозначно выбирает антонимическое прочтение и усиливает степень реализации признака: заль отнюдь не были переполнень = 'было довольно мало народу':

И хоть зальы фестивальных спектаклей ввиду устоявщейся хорошей погоды отнюдь не были переполнены, эта связь состоялась (Экран и сцена». 06.05.2004).

Однако употребление отнюдь не ограничивается случаями, когда оно применяется к признаку, встроенному в некоторую очевидную биполярную шкалу, отрицание которого переключает значение признака на противоположную часть шкалы. Появление такой шкалы может быть имплицировано самим словом отнюдь. Рассмотрим следующий пример:

(35) Не сущуествует дома, где проходила большая часть жизни Командора в той странной нигилистической семье, где он был третий и где помещался штаб лефов, гонявших чаи с вареньем и пирожными, покупавиимися отнюдь не в Моссельпроме, который они рекламировали, а у частников - известных еще с дореволюиионного времени кондитеров Бартельса с Чистых прудов и Дюваля с Покровки, угол Машкова переулка (В.П. Катаев. Алмазный мой венец. 1975-1977).

Притом что само по себе не в Моссельпроме означает просто 'в другом магазине', отнюдь не в Моссельпроме означает 'в более престижном и дорогом'. Наличие этой оценочной шкалы имплицировано словом отнюдь; ее содержание раскрыто в последующем фрагменте текста (смысл 'вопреки тому, что можно было бы предположить', как уже говорилось, содержится в самом отрицании, но он 
«усиливается» словом отнюдь, т. е. отнюдь выполняет здесь одновременно также иллокутивную функцию) $)^{6}$.

Другой пример:

(36) Ольга Виторт систематически посещала фитнес-клуб и время проводила там отнюдь не в косметическом кабинете и не в солярии (А. Маринина. Ангелы на льду не выживают. 2014).

Если извлечь из этой фразы слово отнюдь, то останется в чистом виде отрицание: проводила время не в косметическом кабинете и не в солярии = 'проводила время в другом месте'. Вставка отнюдь говорит о том, что это «другое место» в чем-то противоположно названным. В чем именно, т.е. в какую шкалу встроены упомянутые в конструкции с отнюдь объекты, ясно только из контекста ср. предшествующий тексту (36) фрагмент (37), из которого следует, что в примере (36) имеется в виду противопоставление производимых в косметическом кабинете и в солярии расслабленных процедур, служащих красоте и удовольствию, - производимым в каких-то других подразделениях фитнес-центра суровым тренировочным упражнениям, служащим укреплению мышц:

(37) Мало кому удавалось увидеть ульюку на ее красивом лище, а те, кому довелось по тому или иному (но ни в коем случае не романтическому) поводу коснуться ее руки, плеча или спинь, например подавая пальто или помогая выитти из машины, ощутили стальные мускульл сильного, хорошо натренированного тела (А. Маринина. Ангелы на льду не выживают. 2014).

Однако бывает и так, что содержание шкалы, имплицируемой словом отнюдb, остается неизвестным. Ср. следующий пример:

(38) Глеб посмотрел на Борьку. Борька был высокий, тощчий, носатый и вполне себе обаятельный, но Глеб по опьту знал, что Мариша ищет в мужчине отнюдь не обаяние (А. Иванов. Комьюнити. 2012).

Существует некое «общее мнение» - что женщина ищет в мужчине обаяние; используя отрицательное предложение, говорящий утверждает, что в данном случае это не так: ищет не обаяние значит 'ищет что-то другое'. Слово отнюдь в примере (38) указывает на то, что это «что-то» в каком-то отношении противопоставлено обаянию. Но в каком именно, остается неясным, поскольку качества, образующие релевантное множество (мужских достоинств, которые могут привлекать женщину), не упорядочены в форме шкалы, так что отрицание не позволяет выбрать ни одно из них. Очевидно, говорящий имеет в виду некоторую оценочную шкалу, на которой обаяние и то неназванное качество, о котором идет речь, находятся с противоположных сторон. Отнюдь здесь, конечно же, выполняет также иллокутивную функцию - увеличение «силы опровержения» применимости общего мнения к обсуждаемому случаю.

6 Эффект отрицательной конструкции отнюдь не в Моссельпроме усиливается за счет очевидной аллюзии к знаменитому рекламному лозунгу Маяковского «Нигде кроме как в Моссельпроме». 
В примере (39) альтернатива опровергаемому при помощи отнюдь мнению названа в последующем контексте. Но она не является противоположностью Р, и главное - никак не выводится из утверждения не Р. Это просто некоторый иной взгляд на вещи:

Однако Дон Гуан отнюдь не вульгарный развратник-повеса. Он-человек эпохи Возрождения, кипящчий всей полнотой жизненных сил, безбожник, бросающий смельй вызов верованиям и предрассудкам средневековья (Переписка в icq между agd-ardin и Колючий друг. 18.12.2007).

Хотя для характеристики вульгарный развратник-повеса можно себе представить некую противоположность, не она здесь имеется в виду. В предложении (39) говорящий утверждает, что P неверно, а верно некоторое другое утверждение Q, и при этом Р и Q противоположны лишь в том отношении, что Р имеет отрицательную коннотацию, а Q - положительную.

Итак, отнюдь производит «усиление» отрицания в двух отношениях — дескриптивном и иллокутивном. При этом дескриптивное усиление возможно только в случае антонимического отрицания, т. е. такого, которое переключает значение признака на противоположную зону шкалы. Для неоднозначных слов отнюдь выбирает скалярное значение и взаимодействует с ним - или же «вынуждает» (coerces) из слова возможное скалярное понимание. Если скалярного значения у слова нет, и оно не может быть «вынуждено», то и реализация дескриптивной функции отнюдь невозможна.

Так, для предложения Это произошло не вчера вставка отнюдь возможна только при понимании слова вчера в переносном значении 'недавно', имплицирующем биполярную шкалу; соответственно, отнюдь не вчера означает 'достаточно давно', см. примеры (40)-(44). Если же говорящий имеет в виду, что обсуждаемое событие произошло не вчера, а в какой-то другой конкретный день, отрицание имеет обычное значение 'неверно, что Р', несовместимое со значением отнюдь; соответственно, вставка отнюдь, скорее всего, невозможна, ср.: ??Это произошло отнюдь

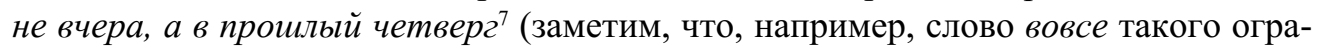
ничения не имеет: сказать Это произошло вовсе не вчера, а в прошльй четверг можно). В [НКРЯ] имеется пять примеров на последовательность отнюдь не вче$p a$; во всех пяти вчера имеет значение 'недавно':

И сложилась такая картина отнюдь не вчера (Голос эпохи. 2012);

(41) Таким образом, убеждаемся, что холст натянут на подрамник отнюдь не вчера (Д. Рубина. Белая голубка Кордовы. 2008-2009);

${ }^{7}$ Мы сделали оговорку «скорее всего», потому что в случае опровержения только что высказанного другим говорящим мнения вчера может иметь буквальное (не скалярное) значение, ср.: - Это произошло вчера. - Нет, это произошло отнюдь не вчера (где отнюдь выполняет исключительно иллокутивную функцию). Заметим, что в отрицательном предложении со словом вчера в скалярном значении 'недавно’ никакой полемики может не содержаться; оно выражает самодостаточную независимую оценку. 
(42) Прости, добрый корчмарь, если мы утомили тебя столь долгим и подробнымм рассказом, но твой дом выглядит обжитым отнюдь не вчера (М. Семенова. Волкодав: Знамение пути. 2003);

(43) При этом очевидное несоответствие целей и средств проявилось отнюдь не вчера (Известия. 19.03.2002);

(44) Лебедь, вопреки распространившемуся тезису, отнюдь не вчера появился на политическом небосклоне (Общая газета. 1996).

В примерах (45)-(46) употребление отнюдь также возможно только потому, что пахнет розами употреблено здесь в переносном смысле 'хорошо пахнет'; оператор отнюдь усиливает степень реализации признака 'плохо'.

(45) Пахнет в вашем террариуме отнюдь не розами (Е. Завершнева. Высотка. 2012);

(46) Изящные салонные забавы обернулись десятками миллионов человеческих трупов, которые отнюдь не розами пахнут, так что с возбуждающчим запахом все получилось как надо (Известия. 31.05.2002).

Итак, для реализации дескриптивной функции необходимо, чтобы предикат имел или допускал такое понимание, при котором он оказывается встроенным в биполярную шкалу. В противном случае отнюдь выполняет лишь иллокутивную функцию увеличения силы опровержения некоторого существующего (или кем-то ранее высказанного) мнения, ср.:

(47) Знаете, в чем главное преимущество знаменитых французских коньяков? Отнюдь не в качествах самой лозы, а в качествах дуба, из которого делаются бочки (И. Грекова. На испытаниях. 1967);

(48) Причина моей неприязни, которую я пытался дурацким образом скрыть, заключалась отнюдь не в пледе или калошах и даже не в Людмиле Сильвестровне, а в том, что Иван Васильевич, пятьдесят пять лет занимающийся режиссерскою работою, изобрел иироко известную и, по общему мнению, гениальную теорию о том, как актер должен был подготовлять свою роль (М. А. Булгаков. Записки покойника (Театральный роман). 19361937).

В случае отсутствия возможности встроить признак в биполярную шкалу и одновременно отсутствия некоторого имеющегося заранее мнения, опровержением которого служило бы данное высказывание, - т. е. просто в качестве независимого утверждения некоторого факта - отнюдь не может выполнять ни одну из двух своих функций и его употребление невозможно, ср.:

(49) Сидят, дуются друг на дружку и, где теперь нектар искать, (*отнюдь) не знают (Мурзилка. 2002);

(50) Один лишь сидевиий поодаль учитель пытался что-то заметить, уточнить или возразить, может, но его (*отнюдь) не слушали (В. Быков. Камень. 2002); 
(51) Хорошо или нет, но на огородах и возле хат никого больше не было, никто его тут (*отнюдь) не увидел (В. Быков. Болото. 2001);

(52) Кроме него да матери, работников у них (*отнюдь) не было (В. Быков. Болото. 2001);

(53) И на каждый из них для проверки высаживались матросы, бывшие официантыл. Печально, что они (*отнюдь) не возвращались. То есть поселялись на островах с намерением открыть свой ресторанчик или кафе (Мурзилка. 2003);

(54) Педагог - а за своей дочкой (*отнюдь) не уследила (А. Геласимов. Жанна. 2001);

(55) Им даже обещцали квартиру дать в каменном доме, но (*отнюдь) не дали (А. Геласимов. Жанна. 2001);

(56) Водитель машины остался за рулем и мотор (*отнюдь) не выключал (А. Азольский. Облдрамтеатр. 1997);

(57) Но соседки либо не было дома, либо она ( *отнюдь) не отозвалась (А. Азольский. Облдрамтеатр. 1997);

(58) Достойные люди, спору нет, да только применения им (*отнюдь) не найдется (А. Азольский. Облдрамтеатр. 1997).

В тех редких случаях, когда отнюдь появляется в контексте сообщения о факте, это оказывается не факт, а фигура речи, ср.:

(59) Я чую в вас большой потенцุиал! - провещуал Петр Александрович и, вздохнув, медленно провел ладонью у меня ниже спины. Я отнюдь не была выпускницей Смольного института. И лет мне было больше шестнадиати. Так что с руки или с ноги заехать по морде, невзирая на должность, я была вполне способна. Но... (Т. Соломатина. Акушер-ХА! Байки. 2009).

Здесь не была выпускницей Смольного института означает что-то вроде 'не была романтически настроенной невинной девушкой', т. е. это оценочное суждение, а вовсе не сообщение о факте.

Обязательность переключения на противоположный конец шкалы, присущее слову отнюд , отличает его от совсем и вовсе, указывающих лишь на полноту степени признака, и, соответственно, делает невозможным замену, ср.:

(60) Только у него глаза совсем не открывались (А. Геласимов. Жанна. 2001) $<*$ отнюдь не открывались>;

(61) Если честно, то амулет Великану был совсем не нужен (Мурзилка. 2002) $<$ жотнюдь не нужен>;

(62) Поскольку английский знаю недостаточно хорошо, а франиузский вовсе не знаю, приходится писать по-русски... (Форум: Похороните меня за плинтусом. Фильм. 2009-2011)<*отнюдь не знаю>.

При этом слово вовсе в отличие от совсем имеет также иллокутивное значение усиления отрицания, близкое к соответствующему значению отнюдь; ср. примеры (63)-(64), где употребление отнюдь также возможно: 
(63) Надо понимать, что если именно тебе дан талант, это вовсе не твоя заслуга, нет повода зазнаваться (Известия. 06.08.2001);

(64) ...использование математических методов в некоторой науке само по себе еще вовсе не гарантирует какого-либо реального прогресса в этой науке (А. А. Зализняк. Лингвистика по А. Т. Фоменко. 2000).

В языке XVIII-XIX вв. (мы рассматривали тексты [НКРЯ] до 1870 г.) слово отнюдь имело более широкую семантику: оно было допустимо также по отношению к обычному (контрадикторному) отрицанию, а не только антонимическому, как в современном языке, т. е. оно выражало просто полное отсутствие признака Р (ср. современное совсем не $P$ ).

Среди случаев употребления отнюд, недопустимых по указанной причине для современного языка, можно выделить контекст модальных предикатов, ср. примеры (65)-(68):

(65) Что касается до главы о слоге вообще, - она должна состоять из опьтных наблюдений, из общих замечаний и отнюдь не долюнна претендовать на наукообразное изложение (В.Г. Белинский. Общая риторика Н.Ф. Кошанского. 1844);

(66) Церковь в ските отнюдь не долюнна была иметь никаких богатств и украшений; серебро и золото изгонялось из нее строго (Н.И. Костомаров. Русская история в жизнеописаниях ее главнейших деятелей. Выпуск второй: XV-XVI столетия. 1862-1875);

(67) Священнику отнюдь не подобает властвовать и управлять; их дело свящееннодействовать, а не творить людского строения (Н.И. Костомаров. Русская история в жизнеописаниях ее главнейших деятелей. Выпуск второй: XV-XVI столетия. 1862-1875);

(68) Сообразно этим пунктам, Анна Ивановна, как мы уже сказали, отнюдь не могла назначать начальствующих в войске лиц, как в гвардии, так и в армии: это право принадлежало верховному тайному совету (Н.И. Костомаров. Русская история в жизнеописаниях ее главнейших деятелей. Выпуск седьмой: XVIII столетие. 1862-1875).

В примерах (69)-(74) слово отнюдь употреблено в функции усилительной частицы в контексте предикатов различной семантики, не допускающих встраивания в какую-либо шкалу (что исключает возможность такого употребления в современном языке):

(69) ...лекарь мой предписал мне, в диете, отнюдь не пить английского пива и не писать стихов, ибо как то, так и другое кровь заставляет бить вверх (Д. И. Фонвизин. К И. П. Елагину. 1769) <невозможно в современном языке, потому что неуместно «скорее наоборот»>;

(70) Но мы постараемся доказать, что таковый высокомерный горделивец ни истинныя своея цены, ни высокого достоинства человеческого отнюдь не зна$\boldsymbol{e m}$ (Н.И. Новиков. О достоинстве человека в отношениях к богу и миру. 1777); 
(71) В случае ссоры мужчин между собою до драки отнюдь не доходить, а довольствоваться умеренными выражениями, лучше всего следовать примеру предков и говорить: «Да будет тебе стылно» (И. А. Гончаров. Хорошо или дурно жить на свете? 1841);

(72) Начальникам амбаркаций было внушено отнюдь не терять времени на спасение соседней, погибающей лодки, пробитой неприятельским снарядом, а думать только о том как бы скорее перепльть через реку (Ф. Ф. Торнау. Воспоминания кавказского офицера. 1866-1880);

(73) В видах сохранения народного здоровья, обывателям городов строго предписывалось не бросать трупов падшей скотинь по улицам, а зарывать в землю, отнюдь не снимая кожи (Н.И. Костомаров. Русская история в жизнеописаниях ее главнейших деятелей. Выпуск седьмой: XVIII столетие. 1862-1875);

(74) Если увидишь у брата какую келейную принадлежность, или какое-либо земледельческое орудие, и оно полюбится тебе; - удержи сердие твое, и научи его отнюдь не любить ничего иного, кроме Христа (епископ Игнатий (Брянчанинов). Отечник. 1863).

Это употребление отчасти сохранялось в XX в., однако с точки зрения сегодняшнего русского языка оно является безусловно устаревшим, ср.:

(75) Это подтверждается сообщением Казарновского о том, что О. М. боялся есть, хотя, конечно, лагерная пища была такая, что люди, отнюдь не боявшиеся есть, превращчались в тени (Н. Мандельштам. Воспоминания. 1960-1970).

В языке XVIII в. слово отнюдь могло быть расположено также после отрицательного выражения, ср.:

(76) Каллисфен не знал отнюдь ни Леонада, ни клеветы, которою сей очернил его у Александра (Д.И. Фонвизин. Каллисфен. 1788);

(77) Всяк должен узнать себя, сиречь свою природу, чего он ищет, куда ведет, и ей последовать без всякого отнюдь насилия, но и с глубочайшим покорением (Г. Сковорода. Толкование из Плутарха о тишине сердца. 1766-1794);

(78) Перемена генерал-прокурора подействовала и на Соляную контору, но не к пользе моей отнюдь (И. М. Долгоруков. Повесть о рождении моем, происхождении и всей моей жизни, писанная мной самим и начатая в Москве, 1788-го года в августе. 1788-1822).

Что касается абсолютивного отнюдь, то до 1870 г. в [НКРЯ] зафиксировано всего два примера:

(79) - Для чего же секретное? Отнюдь. Я у ней буду сам, хоть сегодня (Ф. М. Достоевский. Идиот. 1869);

(80) ...и следует ли из того, чтоб ставить тарелки в укор? - Отнюдь. Предки твои действительно подавали тарелки, но они делали это любя и нередко 
получали за то лакомые куски (М.Е. Салтыков-Щедрин. Завещание моим детям. 1866).

В том же значении употреблялось выражение ни отнюдь 'ни в коем случае', из современного языка полностью исчезнувшее, но сохранявшееся вплоть до начала XX в., ср.:

(81) Разве масса, которая вас окружает, стоит выше вас в смысле умственного развития? Ни отнюдь (М.Е. Салтыков-Щедрин. Тихое пристанище. 1857-1865);

(82) - Скажите, Иван Васильич, правда ли, что наши дела в последние годы стали падать? - Ни отнюдь (А. П. Чехов. Три года. 1895);

(83) - А вот, скоро ворота направо. Там еще написано, чтобы сторонним лицуам ни отнюдь не ходить (В. Г. Короленко. Письма. 1910).

В XX в. частота финального «одиночного» употребления отнюдь возрастает, достигая максимума к концу века, и потом начинает снижаться ${ }^{8}$. При этом в целом частота употребления слова отнюдb, как уже было сказано, растет. Так или иначе, отнюдь для сегодняшнего русского языка - полноценное и достаточно широкоупотребительное дискурсивное слово, имеющее совершенно определенную собственную семантику и в полном объеме своих функций не взаимозаменимое ни с каким другим.

\section{Литература}

Апресян Ю.Д. Лексическая семантика (синонимические средства языка). М. : Наука, 1974. 367 с.

Апресян Ю.Д. Правила взаимодействия значений // Апресян В.Ю., Аnpeсян Ю. Д., Бабаева Е. Э., Богуславская О. Ю., Иомдин Б. Л., Крылова Т. В., Левонтина И. Б., Санников А. В., Урысон Е. В. Языковая картина мира и системная лексикография / отв. ред. Ю. Д. Апресян. М. : Языки славянских культур, 2006. С. 110-145.

Богуславский И.М. Исследования по синтаксической семантике: сферы действия логических слов. М. : Наука, 1985. 175 с.

Зализняк Анна A. Многозначность в языке и способы ее представления. М. : Языки славянских культур, 2006. 672 с.

Квятковский А. Поэтический словарь. М. : Советская энциклопедия, 1966. 376 с.

НКРЯ - Национальный корпус русского языка [Электронный ресурс]. URL: http://ruscorpora.ru

Падучева E.B. Русское отрицательное предложение. М. : Языки славянских культур, 2013. 304 с.

${ }^{8}$ Если до 1870 г. оно практически отсутствует, то в период 1871-1970 гг. составляет чуть более 1\% (от общего количества употреблений этого слова), в период 1971-2000 гг. — около $3 \%$, в период 2001-2019 гг. - 2,3\% (данные по основному корпусу [НКРЯ] для поискового запроса «отнюдь перед точкой» + «отнюдь перед восклицательным знаком»). 
Фасмер М. Этимологический словарь русского языка : в 4 т. / пер. с нем. и доп. О.Н. Трубачева. 3-е изд. М. : Азбука-Терра, 1996.

Rey $A$. Dictionnaire historique de la langue française. Vols. 1-3. Paris : Dictionnaires Le Robert, 2000.

\author{
Anna A. Zalizniak ${ }^{1}$, E. V. Paducheva \\ ${ }^{1}$ Institute of Linguistics of the Russian Academy of Sciences \\ Institute of Informatics Problems of the Federal Research Center "Computer Science \\ and Control" \\ of the Russian Academy of Sciences \\ Pushkin State Russian Language Institute \\ (Russia, Moscow) \\ anna.zalizniak@gmail.com
}

\title{
ON THE RUSSIAN WORD OTNYUD' 'NOT AT ALL'
}

The article offers an analysis of the semantics and conditions of the use of the Russian word otnyud' 'not at all.' It demonstrates that the semantic contribution of the word otnyud' within the meaning of a negative sentence is determined by the fact that it enhances the negation in two respects - descriptive and illocutionary. The paradigmatic context for use of otnyud' is that of antonymic negation, i.e. negation of a scalar feature embedded in a bipolar scale. In this case, the negation not $P$ switches the value to the opposite pole of the scale, i.e. in addition to component 'it is not true that $\mathrm{P}$ ' also includes the assertion of the presence of some Q, which is a full-fledged semantic feature, opposite to $\mathrm{P}$. The descriptive function of the word otnyud' is that it introduces a high degree of realization of the feature $\mathrm{Q}$ opposite to $\mathrm{P}$. The illocutionary function consists in increasing the power of the refutation of the opinion which is generally accepted or expressed by the interlocutor. If the negated feature does not enter into a bipolar scale and there is no preexisting opinion, otnyud' cannot fulfill anyone of its functions, and its use is impossible.

Key words: Russian language, semantics, negation, discourse markers, illocutionary force, bipolar scale.

\section{Acknowledgements}

The research has been supported by the Russian Science Foundation project No. 1818-00462 "Communicative-syntactic interface: typology and grammar" realized at the Pushkin State Russian Language Institute.

\section{References}

Apresyan Yu.D. [The Rules of the Interaction of Meanings]. Apresyan V.Yu., Apresyan Yu.D., Babaeva E.E., Boguslavskaya O.Yu., Iomdin B. L., Krylova T. V., Levontina 
I. B., Sannikov A. V., Uryson E.V. Yazykovaya kartina mira i sistemnaya leksikografiya [Language Worldview and System Lexicography]. Yu.D. Apresyan (Ed.). Moscow, Yazyki slavyanskikh kul'tur Publ., 2006, pp. 110-145. (In Russ.)

Apresyan Yu.D. Leksicheskaya semantika (sinonimicheskie sredstva yazyka) [Lexical Semantics (The Synonymous Tools of Language)]. Moscow, Nauka Publ., 1974, 367 p.

Boguslavskii I.M. Issledovaniya po sintaksicheskoi semantike: sfery deistviya logicheskikh slov [Research on Syntactic Semantics: The Scope of Logical Words]. Moscow, Nauka Publ., 1985, 175 p.

Fasmer M. Etimologicheskii slovar' russkogo yazyka [Etymological Dictionary of the Russian Language] (Vols. 1-4, $3^{\text {rd }}$ ed.). O. N. Trubachev (Transl., ed.). Moscow, AzbukaTerra Publ., 1996.

Kvyatkovskii A. Poeticheskii slovar' [Poetic Dictionary]. Moscow, Sovetskaya entsiklopediya Publ., 1966, 376 p.

Natsional'nyi korpus russkogo yazyka [The National Corpus of the Russian Language]. Available at: http://ruscorpora.ru (accessed 12.12.2019)

Paducheva E.V. Russkoe otritsatel'noe predlozhenie [The Russian Negative Sentence]. Moscow, Yazyki slavyanskikh kul'tur Publ., 2013, 304 p.

Rey A. Dictionnaire historique de la langue française (Vols. 1-3). Paris, Dictionnaires Le Robert, 2000.

Zaliznyak Anna A. Mnogoznachnost' v yazyke i sposoby ee predstavleniya [Language Polysemy and the Means of its Representation]. Moscow, Yazyki slavyanskikh kul'tur Publ., 2006, 672 p. 